\title{
The Colonial Modernity of Medicine Advertisements in the Canton Times
}

\author{
Si-jie $\mathrm{LI}^{1,{ }^{*}}$ and Jia-ke $\mathrm{HAN}^{2}$ \\ ${ }^{1}$ Jinan University, School of Journalism and communication, Guangzhou, China \\ ${ }^{2}$ Jinan University, School of Journalism and communication, Guangzhou, China \\ ${ }^{*}$ Corresponding author
}

Keywords: Colonial modernity, Colonial medicine, Medicine advertisements, Canton Times.

\begin{abstract}
Modern medicine as a kind of cultural power, is not only taken as a tool of the western colonists, but also turns into one of the goals for the local colonized people to pursue modernization. How medical science developed under the impact of colonialism is the mainly discussed problem in this article. Since the western modernity was transmitted into Guangzhou under the semi-colony background, this article analyzes the medicine advertisements in Canton Times and the various social relationships of its advertiser (company or individual). It is found that the transmission of western medical science was conducted by the colonists and meanwhile was accompanied with a dynamic process of learning, imitation and revision by the local.
\end{abstract}

\section{Introduction}

The period from 1910s and 1930s represents the beginning of modernity for many places around the world, not only in Europe and America, but also in Asia. Constrained by the existing social and cultural modes, economy and various political conditions, modernity comes into beings. Under the impact of politics and economy, the modern transformation of Asia is largely dependent on the power of colonialism. It's for sure that medical knowledge and technology strength is also a representation of modernity, the development of modern medicine in Asia can never be separated from the impact of colonialism.

The so-called colonial medicine is brought in by the colonists in order to guarantee the health of colonists. Thus, it emphasizes too much the single-direction input or the mandatory implant from colonists [1]. Actually, modern medicine is not only taken as a tool of the western colonists, but also turns into one of the goals for the local colonized people to pursue modernization, when it, as a kind of cultural power, spreads into the non-western area. Recently, the academic circles have been discussing quite frequently about the relationship of the modernity in East Asia and colonialism. Colonial modernity was first put forward by Tani E. Barlow in 1993, which surpassed the traditional analysis of colonial rule, which highlighted the binary opposition of suppression (or exploitation) and resistance [2]. Instead, she advocated the coexistence of colonialism and modernity. Robinson \& Shin (1999) researched on the colonial period of the North Korea and stressed the complicated relationship among colonialism, modernity and nationalism [3]. The academic circles are gradually giving up the traditional western-centered and colony-marginalized concepts, that the modern technology is not transmitted from the center to the marginalized areas in a single 
direction, but producing unique sparks of modernity when the western culture meets and collides with each other [4].

How medical science developed under the impact of colonialism is the mainly discussed problem in this article. The early Republic was a turning point for the transformation of China from traditional to modern society. Guangzhou, Shanghai, Tianjin and other cities with the Concessions stepped into modern society earlier than other cities in China and came into the earliest shape of modern cities. The Shameen Concession of Guangzhou was the products of semi-colony and its capitalism could even be in pace with the western world. On the one hand, it was the resistance against the feudal system and ideology, which dominated the China for a long history; on the other hand, the western modernity was transmitted into Guangzhou under such a semi-colony background.

\section{Study Object and Methods}

The paper selects the medicine advertisements in Canton Times, a local English newspaper established by Chinese in Guangzhou, as the study object for analysis. The Canton Times was established in Sep. 15 ${ }^{\text {th }}$ [5], 1918 and known as the only daily English newspaper reporting the affairs of Guangzhou. As the Guangzhou military governmental official paper in English, the Canton Times was the most important English-versioned local metro newspaper in South China at that time[6]. Its distribution range was mainly in Guangzhou, but not limited in Guangzhou only. It's mainly published for foreigners and the local elites. Different from Chinese papers and English papers established by foreigners, the Canton Times in English created by Chinese provides us a unique perspective, that the medicine advertisements in Canton Times not only display the advanced medical technologies and ideas from colonialism, but also carry the development process of the local medical science.

The paper first analyzes the contents of medicine advertisements in Canton Times and then analyzes the various social relationships of advertiser (company or individual) in order to study how the modern medical science was transmitted into Guangzhou under the semi-colony background.

\section{Medicine Advertisements and Colonial Modernity}

\section{Colonial Advertisements}

The author found plenty of advertisements on pharmacies and hospitals in Canton Times. Table 1 is the unrepeated statistics of all those institutions in this paper.

In advertisements of pharmacies and hospitals, at least half of them were made by foreign enterprises. Those medical institutions were related to western medicine, except that Jie Shou ge didn't mention about the selling of western medicines. So it could be seen that the western medicine at that time was on the market of Guangzhou. The Union Dispensary also sold dental instruments. The circulation of these instruments on the market tells that the western dentistry was recognized by the locals, which indicates the acceptance of new technology. Different completely from the secondary role of instruments in traditional Chinese medicine, which laid stress on the direct diagnosis of diseases by the doctor independently, the modern technologies required for the diagnosis assisted by instruments. 
Table 1. Advertisements of pharmacies and hospitals in Canton Times

\begin{tabular}{|c|c|c|c|c|}
\hline $\begin{array}{l}\text { Numbe } \\
r\end{array}$ & Advertiser & Content of Advertising Copy & Address & Notes \\
\hline 1 & $\begin{array}{l}\text { Chung Mei Drug } \\
\text { Company, Limited }\end{array}$ & $\begin{array}{c}\text { Prescriptions! Have yours } \\
\text { Dispensed at Chung Mei Drug } \\
\text { Company, Limited }\end{array}$ & The bund & - \\
\hline \multirow[t]{2}{*}{2} & $\begin{array}{l}\text { The Union } \\
\text { Dispensary }\end{array}$ & $\begin{array}{c}\text { Drugs, Chemicals \& Patent } \\
\text { Medicines; }\end{array}$ & $\begin{array}{l}\text { West } \\
\text { bund }\end{array}$ & - \\
\hline & & $\begin{array}{c}\text { Surgical and Dental Instruments, } \\
\text { etc. }\end{array}$ & & \\
\hline 3 & Dr. T. Yamasaki’s & $\begin{array}{l}\text { Japanese Dental Surgeon. No } \\
\text { Charge for Examination }\end{array}$ & Shameen & Japanese \\
\hline 4 & $\begin{array}{l}\text { A.S. Watson \& } \\
\text { Co.Ltd }\end{array}$ & Dispensing Prescriptions & Shameen & English \\
\hline 5 & Jie Shou ge & $\begin{array}{l}\text { Medicinedew. Drops in the feet and } \\
\text { all kinds, of the External Diseases. }\end{array}$ & $\begin{array}{l}\text { Yen Che } \\
\text { St. }\end{array}$ & Local \\
\hline 6 & $\begin{array}{c}\text { Stout Memorial } \\
\text { Hispital }\end{array}$ & Chinese Yong Man Wanted & $\begin{array}{c}\text { Wucho } \\
\text { w }\end{array}$ & $\begin{array}{c}\text { A church } \\
\text { background }\end{array}$ \\
\hline
\end{tabular}

Stout Memorial Hospital was established by the donation of an American Christians and known as the first formal western hospital in Guangxi Province. Later, it developed into the biggest modern western hospital with best conditions in South China. Its recruitment advertisements on Canton Times presented the desire of western hospitals for talents, knowing English and Chinese apart from professional knowledge and pharmacy management. As was stated above, plenty of recruitment information in Canton Times required the employee's knowledge of English, which showed that the acceptance of transmission of western science and technology demands well understanding of the language and culture of the foreign countries, since language acquisition was the most significant means to know and learn the modernity of westerners. In addition, Dr. T. Yamasaki's was a dental hospital established in Hong Kong by Japanese, which was quite influential at that time and enjoyed a long history [7]. Dr. T. Yamasaki's in Canton Times was its branch company, from which we can see its strong power.

Those hospitals were one-way transmissions by colonists through their special rights to input the medical modernity to their colonies. Moreover, the western hospitals were quite popular in the colonies at that time, as they brought scientific and hygienic medical idea to the colonies. The existing view in academic circle that colonists transmitted the new medical idea into China was shown in Canton Times.

\section{Imitation and Innovation by the Local}

While considering the medical institutions, we must take into account the factor of human beings to understand better the dynamic process of modernity of medical science transmitted into the colonized Guangzhou. In other words, the contributions to the popularity of modern medicine must be considered from the perspective of the returned overseas Chinese doctors and the local medical institutions, given the direct influence of colonist doctors and medical institutions. 
Table 2. Basic information on doctors (advertisers) in medical advertisements of Canton Times (1919-1920)

\begin{tabular}{|c|c|c|c|c|c|c|}
\hline Number & Name & Gender & $\begin{array}{c}\text { Educatio } \\
\mathrm{n}\end{array}$ & $\begin{array}{c}\text { Degre } \\
\mathrm{e}\end{array}$ & Specialty & Address \\
\hline 1 & Leung T. M. & male & America & - & Dental & The Bund, \\
\hline 2 & $\begin{array}{l}\text { Dr. Andrew } \\
\text { Wu Gayson }\end{array}$ & male & - & Doctor & $\begin{array}{l}\text { Peculiar diseases } \\
\text { found in South } \\
\text { China }\end{array}$ & Yan Chai Street \\
\hline 3 & $\begin{array}{l}\text { Dr. C. S. } \\
\text { Kwong }\end{array}$ & male & America & - & Dental \& Surgeon & West Bund \\
\hline 4 & $\begin{array}{l}\text { Antonio } \\
\text { Azivido }\end{array}$ & male & Brazil & Doctor & Dental & The Bund \\
\hline 5 & Chan Tit Van & male & - & - & Physician \& Surgeon & Ngau Yu Bridge \\
\hline 6 & $\begin{array}{c}\text { Leung Quan } \\
\text { Wai }\end{array}$ & female & 一 & - & Professional & Hoo Yan St. \\
\hline 7 & $\begin{array}{l}\text { Dr. T. Y. } \\
\text { Huie }\end{array}$ & male & - & 一 & Dental & The Bund \\
\hline 8 & $\begin{array}{l}\text { Dr. C. B. } \\
\text { Chan }\end{array}$ & male & 一 & - & Dental & Tai Hong How \\
\hline 9 & Dr.Jose.C & male & - & 一 & Physician \& Surgeon & - \\
\hline 10 & $\begin{array}{c}\text { Dr.C.S.Kwo } \\
\text { ng }\end{array}$ & male & - & - & Dental & West Bund \\
\hline
\end{tabular}

Table 2 is the unrepeated statistics of clinics and corresponding advertisers in Canton Times (1919-1920). It's observed that 10 doctors opened clinics at that time. In advertisements, two of them possessed the Doctor Degree, which was clearly expressed; three of them were returned overseas Chinese, who were mainly educated in America (North and South America). They have been well trained about their medical science abroad and specialized in dentistry.

At that time, the business was flourishing and market was booming, including the medical market. The medical profession also became diversified to satisfy varieties of demands of customers of all walks of life. Dental problem was part of the surgery. The specialization in medicine industry was just one of the factors, leading to the booming of dental science. More importantly, the demands of patients were essential for the emerging of medical science, as the medical market was dominated at that time by the model, that patients visit a doctor at the cost of themselves. The literatures on the changes of dental science pointed out that mouth and teeth turned into a new knowledge about body in the middle of the 19th century [8]. Those changes were explained by the functional analysis, in which the increasing demands of medical treatment about dental diseases contributed to the flourishing of dental science. In addition, people stressed much the natural expression of emotions in Europe of the 18th century. The toothy smile began to become a new trend of the emerging capitalists. Dental health care products and dental service to maintain the good looking of mouth turn a new fashion of the consumption society. The traditional Chinese physicians were more often general practitioners. The prosperity of dental science actually indicated the formation of specialization in medical science in Guangzhou, which was an important characteristic of divisions of modern vocational skills. Besides, it can be seen that the addresses of 
clinics were concentrated in the Bund near Shameen, showing that the western medical science had become a force at that time and began to cluster.

Doctor Leung T. M was one of the founders of the Methodist Episcopal Church in Guangdong, one of the establishers of the Jili community, one of the earliest followers of the democratic revolution, led by Sun Yat-sen and later joined into Chinese Revolutionary League for the revolution careers. In 1908, he returned to China and participated in the founding and development of the Jili community and the Methodist Episcopal Church. In addition, he, as a dentist, opened a clinic in the Bund to serve the people around [9]. Dr. C. S. Kwong was an overseas student, studying dental science in California in America, where he had 12 years of clinical experience. In the early Republic, Dr. C. S. Kwong went to America for further study on dental science. After graduation, he wished to get the medical license in San Francisco. But Chinese at that time were discriminated extremely by Americans, who once laughed him off and said that, 'You, the yellow can only stay in Chinatown and be a doctor there. You can't make it anywhere else.' At that year, Dr. C. S. Kwong just completed his medical school and didn't get married. Out of deep love to his mother country, he followed Sun Yat-sen and assisted him to raise money and promote his thoughts. Sun Yat-sen was suffering from dental disease. It's also Dr. C. S. Kwong who gave treatment to him. At that year, his clinic had been equipped with electrical apparatus. But he couldn't bring the electrical dental drill when visiting a patient. So he had to take a pedal dental drill [10].

The modernity of medical science is indicated by the transmission of modern medical technologies. Dr. C. S. Kwong, as a dentist, had begun to use electrical dental drill to treat dental diseases. Andrew Wu Gayson also claimed in advertisement that he's an expert, who did professional research on diseases in South China and brought back to China "new treatment". So it can be concluded that some diseases couldn't be cured by the traditional Chinese medicine. So he had to tell others that he had learnt something new abroad in advertisement. Actually, Andrew Wu Gayson was not only a member of the Shanghai Public Medical Association, but also the head of the organization. In 1928, when he was in Shanghai and had a new treatment method for "encephalitis and red fever", Wuhan Road Commercial Association advocated "setting up a medical center, publishing journals with hygienic common sense and distributing them house to house" and meanwhile "preparing diagnosis coupons, handing them out to the poor and diseased families and visiting Andrew Wu Gayson's clinics in No. 13 of this road for treatment". Andrew Wu Gayson not only came back to China with new technologies, but also established teams to spread new technologies and new medical ideas. The teams and organizations of western medicine in the early Republic were mainly composed of overseas Chinese doctors, who returned to China instead of letting the colonists (missionary physicians) continue dominating the medical teams. As a result, the Chinese and foreign medical powers kept a balance. They studied the modern medical science and taught the Chinese the modern medical philosophy of "hygiene", "health" and "science".

The modernity of the society in China, as a kind of exogenous social change, is usually characteristics of the pursuit and following of the western advanced countries. Based on the above analysis on the doctors and medical institutions in Canton Times, the exogenous feature is not difficult to understand. The social elites more often reaffirmed themselves to be one of the global citizens and remove the inferiority to colonists by learning medical science, if the Asian were shamed of being a member of the second race. The overseas Chinese doctors were endorsers of the health concept in 
the new era and showed that medical science had become the power for colony society in pursuing for the civilization progress.

\section{Conclusions}

The modernity of medical science in the semi-colonial Guangzhou was first what the colonists (including the individual doctors and institutions) had brought into China. Then in the dynamic process of the transmission by colonists, the overseas Chinese doctors had a better knowledge of the local customs than the colonists, were capable of combining the western medicine with the physical quality of the local people and developed better treatment methods. Thus, the non-western society was changing from being passive to positive in utilizing the western medical science and applied what they learned in their own environments.

Given the medical science and the colonial modernity of the early Republic, the colonists did have powerful knowledge and economic advantages to implant the modernity of medical science into the local society. But the contributions of those overseas Chinese doctors should never be neglected. From the advertisements, it's observed that the birth of the overseas Chinese doctors teams pushed the transmission of modernity not be dominated by the doctrine of western science center. The transmission of western medical science was conducted by the colonists and meanwhile was accompanied with a dynamic process of voluntarily learning, imitation and revision by the local. It was not just a simple process of giving and receiving. Certainly, if taken into account the traditional Chinese medical science at that time, the blending process of Chinese and western medical science would be another kind of dynamic process: resistance and acculturation. But that was not the problem to be solved in this paper and was left for further study by later researchers.

\section{Acknowledgement}

This research was financially supported by the Jinan university outstanding undergraduate and recommendation examination graduate scientific research innovation cultivation Program, Consumer culture and colonial modernity in English newspaper advertisements in the early of the republic of China.

\section{References}

[1] Fan Yanqiu (2005), Epidemic Disease, Medical Science and Colonial Modernity: Medical Science History in Japanese Colonial Period (Vol. 32), Daoxiang Press.(in Chinese)

[2] Liang Qizi \&Yu Xinzhong (2007), Medical History and "Modernity" in China, Chinese Social History Review (8), 8 (in Chinese)

[3] Barlow T E. Colonialism's career in postwar China studies [J]. positions, 1993, 1(1): 224-267.

[4] Shin G W, Robinson M. Introduction: rethinking colonial Korea[J]. Colonial modernity in Korea, 1999, 4.

[5] Modern Economic and Social Situation of Guangzhou Port: Guangdong Customs Reports Collections [M], Jinan University Press (in Chinese) 
[6] The Columbia evening Missourian., June 27, 1921, Last Edition, p.6.

[7] Lan Jing, Hong Kong Immigrants and their Living Conditions in Modern Times (1841-1941) [J], Journal of Jinan University: Philosophy and Social Science Edition (in Chinese)

[8] Nettleton S. Power, pain, and dentistry [M]. Open University, 1992.

[9] Chen Manqing, Kingdom of God in Jili Village of Guangzhou in Late Qing [J/OL], $\mathrm{Pu}$ Shi Institute For Social Science. http://www.pacilution.com/ShowArticle.asp?Articl $\mathrm{eID}=4524$

[10] Sun Yat-sen \& Pui Ching (1) [J/OL], the Pui Ching (in Chinese) 